\title{
Piotr Domeracki, Rozstaje samotności. Studium filozoficzne [The Crossroads of Loneliness. A Philosophical Study], Cracow: Zakład Wydawniczy NOMOS, 2016, p. 380
}

DOI: http://dx.doi.org/10.12775/RF.2016.045

Loneliness awakens deeply ambivalent attitudes and emotions in people. On the one hand, in the perspective of everyday chores and multiplicity of social contacts, it appears as a space for respite, relax, being with oneself and finding oneself, the space for being-for-oneself. On the other hand, it seems a threat, seclusion, an inability to be with others, being restrained in the circle of one's own affairs, worries, without the possibility of sharing them, even in part, with a close person. Loneliness in such a depiction demands a break towards being-with-oneself. This ambivalence is also present in the counsel formulated by psychologists, therapists, and in the writings of philosophers. Some of them (like Schopenhauer) praised loneliness, others (like Hume) saw it as a contradiction to the nature of man and society. Still, others sought for via media, pointing to the polarity of human existence. Nietzsche wrote, "Those who live alone do not speak too loud nor write too loud, for they fear the hollow echo - the critique of the nymph Echo. And all voices sound different in solitude (The Gay Science).

What is loneliness? Is it possible to provide a satisfactory definition of this experience of human life that is both hopeful and frightening? Is it sensible and possible to create a philosophy of loneliness that would try to capture the logos of loneliness, describe its nature, and grasp its philosophical implications? In Polish studies there are generally no studies in this area; it is only possible to refer to the dissertations and articles collected in the volume Understanding Loneliness: an Interdisciplinary Study (ed. P. Domeracki, W. Tyburski, Torun 2006) and in the monographic issue of "Christian Philosophy" entitled "Osoba i samotność" [A Person and Loneliness] (Poznan 2015). The image is complemented by a few articles scattered across various scientific journals. However, the issue of loneliness in philosophical optics calls for scientific studies in the form of books providing both a synthetic presentation of the rich- 
ness of this subject matter and analyses of specific issues. Here, we could point to the translation of a work by A. Storr entitled Solitude. A Return to the Self. (trans. Prokopiuk, P.J. Sieradzan, Warsaw 2010), although it is difficult to recognise it as a study in the area of strictly understood philosophy of solitude and more as the study placed within the psychology of solitude. That is why it is so gratifying to find in the Polish bookmaking market the monograph by Piotr Domeracki, a philosopher affiliated with the Nicolaus Copernicus University of Torun, who has for many years been creatively dealing with philosophical monoseology, or, one may even say, has been the founder of its framework and shape. The reviewed book is a synthetic and precursory introduction into the meanders of thinking of solitude from philosophical perspectives. Let us briefly discuss its structure. A broad introduction draws up the rudiments of the philosophy of solitude, defines its goals, methodology, and points to the demand for and importance of philosophical research into the phenomenon of loneliness. The analytical and problem core of the book is constituted by four chapters divided into two parts. The first ("Individual metanarrative") discusses the onto-existential (loneliness of existence), contemplative (constructive loneliness) and liberal trend (freedom doomed to solitude). The second part ("Communionistic metanarrative") discusses the collectivist, practical, and dialogal current in one chapter, focusing on the views which accentuate the destructiveness of loneliness, understanding it as something that distracts man from his real vocation - living in collectivity, society, community. Each chapter ends with a synthetic summary. Reading the book is facilitated by the use of indexes (personal and material), explanation of key words and concepts, the graphs and diagrams provided. The monograph is written in a beautiful language and, what is worth emphasising, develops an interesting proposition of monoseological semantics, thus resulting in very interesting samples of philosophical word formation with reference to classical languages. In addition to the philosophical functions within the discussed subject matter, the said proposals are in a vast majority a very successful attempt to enrich the Polish language in the field of humanistic discourse.

While weighing the philosophic importance of solitude, Domeracki notes: «One should consider whether loneliness does not happen to be the central problem of philosophy, or perhaps even of the whole of the humanities; or in a weaker version: can't we assume that loneliness is one of the main philosophical problems, or perhaps humanistic in general?; or in the weakest version, for which I opt the most: isn st it perhaps true that loneliness, despite the underestimation that it encounters in philosophy, is indeed a philosophical problem, has a specific philosophical profile, and therefore it deserves or even should be addressed in philosophy with due solemnity» (p. 31). The purpose of the monograph is 
to precisely highlight the philosophical dimensions of loneliness, and thus, to justify the thesis of their existence and importance. The author himself declares: «I tried to define the philosophical dimension of solitude, as I have described it, on the basis of historical material consisting of philosophical texts from different epochs, schools and traditions, from antiquity to modernity» (p. 302). Therefore, the book constitutes an ambitious attempt to introduce thinking of loneliness into philosophy by referring to classical philosophical texts, their analysis and classification. Domeracki succeeds in deriving from them the content which escapes the commentators, and sometimes perhaps the authors themselves.

The concept of solitude is not explicit, hence there appears the need for an agreement related to its definition and classification. We read: «by loneliness I shall understand the phenomenon of human existence, which is a certain kind of a more or less permanent individual distinction, considered within a particular system of references, and which is experienced unconsciously, preconsciously or consciously» (p. 40). Certain doubts are raised by the distinction between the unconscious and preconscious experience, and reading the entire book does not lead us towards its understanding. Moreover, there is a question of the description of the unconscious experience of loneliness, presumably deeply entangled in various preconceptions originating in the psychoanalytic paradigm.

The author of the monograph, as already mentioned, divided his argument into two metanarratives. The individualist orientation emphasises the fundamental role and axiological origin of an individual, and the communionism - of a community. Hence there exists individualism «domesticates loneliness», and communionism «the living in a community» (p. 58). The author stresses the opposing nature of the both propositions in the spaces of the philosophy of solitude: «individualistic - propagating solitude, and communionistic - devaluing solitude» (p. 304). Thus, the division emerges from a clear criterion, and seems to be well aligned with the philosophical positions on loneliness. However, in the context of such a definition of both great narratives, a number of doubts and questions arise while reading the book. Let us signal some of them. Does the onto-existential current that perceives an individual in the perspective of ontological loneliness propagate it in any way? After all, one can perceive the radical distinction of human beings on the level of ontological solitude and propagate pro-social attitudes at the level of actual choices regarding specific forms of existence. However, if we were to see this in the perspective of propagating the solitude, as the author suggests, a question would arise whether in the thus defined individualistic trend there is room for Heschel, Ebner or Levinas, even if limited to his early thought? Didn't the latter, whilst speaking of being, emphasise the role and, in a sense, the task of evasion (l'evasion) from the 
totalising existence? In the context of these and other doubts, it seems that the onto-existential current locates itself somewhere above the both narratives, constituting another level of description of human condition in relation to the diagnosis of the nature of the actual existence and thus its axio-normative valuation. The discussed trend and its isolation by the author of the monograph should be considered very significant. The indication of the level of loneliness reaching the foundations of human existence and hidden in the structure of the being itself appears as a very promising trajectory of thinking. "To exist means to be lonely. The loneliness of existence is not an object of choice just as existence itself" (p. 99). This unique attachment to one's own existence implies the state of ontologically conditioned solitude. However, cannot we take a look at it from a slightly different perspective where the realisation of it may not only translate into lowering of the quality of life but also into its growth? Finally, cannot the ontological loneliness lead to one's realisation of that mystical unity in existence, as for instance Gabriel Marcel wanted? In this perspective, we should rather speak of communionistic optics. And such clues of thinking, contained in the above questions and doubts, point to the separateness of the onto-existential current with respect to both metanarratives already entangled in the factual order and affirmative or negative evaluation of loneliness as a certain, essentially unnecessary, phenomenon of human existence. It is associated with the atrophy or pathology of human relations with the world, mainly the world of people. One of the dimensions of this phenomenon is described by a trend referred to in the book as contemplative, affirming loneliness, according to the author of monographs, a phenomenon that is not well recognised here, whereas another dimension is captured by the liberal current, centred on the loneliness-in-freedom and freedom-in-loneliness. The analyses presented in these chapters show the author's excellent scientific background and the heuristic fertility of the selected research fields.

The second part of the book which describes the positions in the communionist narrative consists of a single chapter that gives the first impression later confirmed in the course of the reader's familiarisation with this part of the analyses, of a clear "deceleration" of analyses, interpretative and ordering inventiveness of Domeracki. He discusses particular trends in brevi using synthetic shortcuts, understatements, which sometimes result in simplifications. Doesn't the ontology of a human person present in Buber's philosophical writings deserve an extensive treatment? Isn't this the right place for Levinas's thought due the introduction of extremely valuable intuitions in this type of monoseologic narrative? Does the division into two metanarratives meet the logical requirements of classification and aptly order the positions discussed? Doesn't the book lose its fundamental division into the objective (I am lonely) and subjective (I have a sense of loneliness) dimension of loneli- 
ness, which, as it seems, is fundamental for the discussed matters? Still, the distinction of the individualist and communionist option has its strong points and brings a certain order into the monoseological discourse, indicating the contrariness (whether it is of a radical character is the subject of a separate discussion) of two great narratives. Proper reflections would require specific, detailed decisions classifying Domeracki and perhaps an introduction of a more elaborate typology of solitude. Questions and doubts can be multiplied. On the one hand, they point to certain inadequacies arising in the course of reading the discussed book, whilst on the other hand, they result from the reader's sharing the author's way of thinking, from an attempt at a slightly different structuring of the presented problems and material. It does not reduce the value of the monograph reviewed, whose importance cannot be overestimated.

The book is written with an enormous philosophical and erudite culture. The author has read and recalled most of what is important and interesting for the philosophy of loneliness. The bibliography occupies nearly 50 pages! In addition to the excellent philosophical erudition, Domeracki showed great all-culture competences, with particular regard for fine literature (cf. the great analysis of the "Steppe Wolf" by H. Hesse or the works by H. D. Thoreau). One might insist on the presence of particular authors (as for instance Kafka, Mrożek, or Ciorana, Guardini, Stein, Wojtyła and, perhaps, Ricoeur who is treated very marginally) or giving more attention to certain concepts present in contemporary thought (e.g. the authenticity of existence or Heidegger's mit-sein existence or the assessment of solitude in Fromm's writings, such as Let There Be Man). But this is a matter of the author's choices and smaller or greater sensitivity to certain philosophical or literary trends.

Solitude is a word that evokes lively emotional reactions of different polarity. It appears as a burning problem of life, demanding a solution, assuming of a certain attitude. There are numerous psychological and therapeutic books devoted to this subject matter which convince readers to sink into loneliness or abandon it or - in a mixed version - to divide life into periods of loneliness and times when it is broken, enter into a specific dialectic: being-with-oneself - being-with-another. The discussed monograph is a radically different type of reflection. It leaves aside the practical approach, the pragmatic goals of life, focusing on the theoretical description of loneliness and explaining its nature; however, it contains clear existential implications, even pedagogical or self-therapeutic. This makes it attractive not only for philosophers, but also for psychologists or teachers, as well as for anyone who is constantly experiencing different shades of solitude and trying to understand it. The Crossroads of Loneliness is an extremely important monograph in the Polish philosophical market (and not only, hence its publication in English appears to be very desirable). The author of the foreword, Ben Lazare 
Mijuskovic, is right when he says that it will be a reference point for any research on the philosophy of solitude, constituting an inspiration, an ordering thought or points of contention and critical thinking shared with the author. Piotr Domeracki offered us a record of his reflections formulated following many years of studying of the phenomenon of loneliness. Many issues require further thought, detailed analyses, conceptual precision and classifying corrections. The books reveals new horizons and it can be expected that the author will provide further explanations of various problems and issues in his consecutive monographs. In this monograph, the author has accomplished the assumed goals, demonstrated the philosophical significance of the phenomenon of loneliness, established the rudiments of philosophical monoseology. His books has already become and will continue to be the true food for thought! 